\title{
Des-contextualización del derecho de acceso a la información pública por la jurisprudencia constitucional chilena. Comentarios a la Sentencia del Tribunal Constitucional Rol 7425-19-INA de 19 de diciembre 2019
}

\author{
De-Contextualization of the Right of Access to Public Information by the \\ Chilean Constitutional Jurisprudence Comments on the Constitutional \\ Court's Decision, Role 7425-19-INA of December 19, 2019
}

Lorayne FINOL ROMERo ${ }^{1}$

Emercio APONTE APONTE 2

Resumen: Este trabajo analiza una sentencia del Tribunal Constitucional que declaró la inaplicabilidad de los artículos 5ㅜ y 10 de la Ley 20.285 sobre acceso a la información pública, así como del artículo 31 bis de la Ley 19.300 sobre bases generales del medio ambiente. Esta sentencia considera un conjunto de aspectos controvertidos que descontextualizan el reconocimiento progresivo del derecho de acceso a la información, ignorando compromisos internacionales de los derechos humanos legítimamente pactados.

Palabras clave: Derecho de acceso a la información pública, transparencia de la función pública, derecho internacional de los derechos humanos

\begin{abstract}
The present commentary analyzes a judgment of the Constitutional Court that declared the inapplicability of Articles 5 and 10 of Law 20.285 on access to public information, as well as Article 31 bis of law No. 19.300 on general environmental. This ruling, as detailed in

\footnotetext{
${ }_{1}^{1}$ Abogada Summa Cum Laude y Doctora en Derecho Público por la Universidad del Zulia de Venezuela. Máster en Evaluación de Políticas, por la Universidad Internacional de Andalucía, de España. Becaria Académica en Gobierno Abierto e Innovación del S ector Público, por la Universidad de Chile. Académica Investigadora de la Facultad de Derecho y Humanidades de la Universidad Central de Chile. Correo electrónico: lorayne.finol@ucentral.cl

${ }^{2}$ Abogado Cum Laude y Doctor en Derechos por la Universidad del Zulia de Venezuela. Doctor en Derecho Internacional, por la Universidad de Córdoba de España. LL.M Magna Cum Laude en Derecho Internacional de los Derechos Humanos, por la University of Notre Dame Law School, EEUU. Becario del Instituto Interamericano de Derechos Humanos, San José de Costa Rica. Profesor Colaborador de la Universidad Abierta de Cataluña, Barcelona, España, y Profesor Adjunto de FAMU College of Law, Florida, EEUU. Correo Electrónico: eaponten@uoc.edu; eaponten@alumni.nd.edu
} 
the analysis below, reproduces controversial aspects that create barriers to the effective exercise of the right of access to public information and decontextualizes the principle of transparency of the public function of the InterAmerican human rights standards.

Keywords: Right of Access to Public Information, Transparency of the Public Service, InterAmerican Human Rights Law

\section{Introducción}

El presente comentario de jurisprudencia, analiza aspectos de la sentencia del Tribunal Constitucional Rol 7425-19-INA de fecha 19 de diciembre 2019, donde se declara la inaplicabilidad del Artículo 5ํㅡ y 10 de la ley 20.285 sobre acceso a la información pública y del artículo 31 bis de la ley 19.300 sobre bases generales del medio ambiente, para que surta efectos en la causa caratulada "Productos del Mar Ventisqueros S.A. con Consejo para la Transparencia" de la Corte de Apelaciones de Santiago, por recurso de reclamación Rol Contencioso Administrativo № 379-2018³ . El contenido de este trabajo se estructura de la siguiente manera. En la primera sección se realiza una síntesis del asunto justiciable. En la segunda sección se examinan las dimensiones del problema jurídico debatido a luz del derecho y la doctrina. En la tercera sección se analizan los argumentos de la sentencia por los que se declara la inaplicabilidad del artículo 5ํ inciso $2^{\circ}$ y el artículo 10 inciso $2^{\circ}$ de la ley 20.285 en el caso impugnado ${ }^{4}$. Finalmente, se exponen nuestros argumentos in factum por los que se discrepa de la sentencia.

\section{Síntesis del asunto justiciable}

Preliminarmente, es importante indicar que antes de la decisión de fecha 19 de diciembre de 2019 del Tribunal Constitucional en la que se basa este análisis, esta Magistratura ya se había pronunciado -en varias ocasiones-, en el mismo tenor en las Sentencias Rol №: "2246/2012, 2153/2013, 2379/2013, 2907/2015, 3111/2016, 3974/2018, 4986/2019/, 5950/2019”5. Sin perjuicio de ello, el contexto de la precitada impugnación inicia con una solicitud de acceso a la información pública realizada por Oceanía Inc. el 6 de febrero de 2018 al Servicio Nacional de Pesca y Acuicultura, en adelante SERNAPESCA, en donde solicitó dos informaciones: a) La

\footnotetext{
${ }^{3}$ Corte de Apelaciones de Santiago, Recurso Contencioso Administrativo Rol № 379 - 2018, de 22 de agosto de 2018, cuya tramitación se encuentra vigente a la fecha de realización de este análisis.

" Finol (2019): “Análisis de Impacto regulatorio de la ley de transparencia № 20.285 a diez años de vigencia”, ponencia presentada en las XLIX Jornadas Chilenas de Derecho Público.

${ }^{5}$ Tribunal Constitucional, Rol 7425-INA-2019, de 19 de septiembre 2019. Considerando 10ㅇ.
} 
cantidad y clase de antibióticos utilizados durante los años 2015-2017 y b) Biomasa producida durante los años 2015-2017, ambos requerimientos desglosados por año, por toneladas de producción y por centro de cultivo, por tratarse de información que obra en poder de SERNAPESCA, relacionada con actos, resoluciones y sus fundamentos, dictaminados en ejercicio de la facultad de fiscalización legítimamente atribuida.

Esta solicitud de acceso a la información (en adelante SAI), fue denegada por SERNAPESCA mediante Resolución Exenta $\mathrm{N}^{\circ} 691$ de fecha 27 de febrero de 20186, por referirse a información de terceros cuya publicidad afecta sus derechos. Ante la negativa, Oceanía Inc. recurrió al Consejo para la Transparencia —en adelante el Consejo- para solicitar amparo de su derecho de acceso a la información. En este caso, el Consejo concluyó que respecto de las empresas que se opusieron a la entrega de una parte de la información solicitada, SERNAPESCA estaba impedida de entregarla, alegando que, en esa parte, las empresas no han consentido en la publicación de sus datos sobre cosechas anuales en tales informes. No obstante, respecto a la otra parte de información, según lo explicado por el Consejo, donde "algunas empresas accedieron a la publicación de información sobre cosechas por año en informes publicados por el órgano reclamado era inoficiosa su alegación de reserva sobre el particular"7. Es por lo que en la Resolución el Consejo acogió parcialmente el amparo, respecto a la información de empresas que efectivamente consintieron la publicación de sus datos sobre cosechas anuales contenida en los informes de SERNAPESCA.

En otras palabras, el Consejo ordenó la entrega de la información parcialmente requerida a SERNAPESCA, por no haberse acreditado que la entrega de dicha información afecte los derechos comerciales y económicos de las empresas. Respecto a esta decisión del Consejo, específicamente en lo referido a la protección de los intereses económicos y comerciales de empresas privadas, el Consejo observó que con "la entrega de dicha información [no] afecte[a]derechos comerciales y económicos de las empresas, atendiendo que existe un interés público asociado al conocimiento de tales antecedentes al encontrarse vinculada con una materia que puede comprometer la salud pública”8. En este tenor, la posición que prevalece del texto citado revela que la Resolución del Consejo no incurre en alguna de las causales taxativas

\footnotetext{
${ }^{6}$ Escrito de Descargos presentado por Consejo para la Transparencia, por ante Corte de Apelaciones de Santiago Rol 379-2018, de 14 de septiembre de 2018.

${ }^{7}$ Consejo para la Transparencia, Resolución ROL C1003-18, Decisión Amparo de fecha 14 de marzo de 2018.

${ }^{8}$ CPLT Rol C1003-18, del 2 de agosto de 2018. En esta resolución, el Consejo acogió amparo y ordenó a SERNAPESCA entregar la información desagregada.
} 
de secreto o reserva de la información pública, establecidas taxativamente en la ley y la Constitución?.

Por el contrario, la información amparada por la resolución que admite la solicitud de información de Oceanía Inc. a SERNAPESCA es pública, desde el mismo momento que fue entregada por las empresas a los fines de cumplir con la obligación de transparencia medioambiental establecida en el artículo 31 bis de la ley 19.30010. En consecuencia, conforme al análisis que antecede, dicha información es de carácter público, por aplicación de lo dispuesto en el artículo $5^{\circ}$ y 10 de la ley 20.285, que garantiza el derecho constitucional de acceso a la información, implícitamente reconocido y protegido por artículo 19 ordinal 12ำ y por interpretación progresiva del inciso segundo del artículo $8^{\circ}$ de la Constitución Política. De igual modo, que la ley $\mathrm{N}^{\circ} 20.417$ que modifica en su artículo primero a la ley № 19.300 sobre Bases Generales del Medio Ambiente, cuando establece el derecho de acceso a la información ambiental en el artículo 31 bis. Adicionalmente, y aunque no es el fin de este análisis amicus curiae, en el caso no ha quedado justificado que la información solicitada pudiese suponer perjuicio para los intereses económicos y comerciales de sus titulares, habida cuenta, que una parte de la información solicitada contenida en los informes de SERNAPESCA, fue autorizada por las empresas para su publicación, de conformidad al criterio sostenido en la Resolución de Amparo.

No obstante, la empresa Productos del Mar Ventisqueros S.A., interpuso contra la decisión del Consejo, un reclamo de ilegalidad ante la Corte de Apelaciones de Santiago, fundamentando su procedencia en la causal de reserva del artículo $21 \mathrm{~N}^{\circ} 2$ de la Ley de Transparencia, dado que: "Si bien la información solicitada ha sido entregada al Servicio Nacional de Pesca, ese solo hecho no la convierte en información pública, por lo que no puede ser revelada a un particular, mediando oposición"11. Conforme a ello, el Tribunal Constitucional reiteró al Consejo, que la entrega de información debe circunscribirse dentro de los límites taxativamente fijados por la Constitución y la ley.

\footnotetext{
${ }^{9}$ Es importante recapitular el iter procesal, señalado preliminarmente que contra esta resolución se interpuso reclamo de ilegalidad, por ante la Corte de Apelaciones de Santiago y posteriormente requerimiento de inaplicabilidad, por ante el Tribunal Constitucional, quien admitió su tramitación y ordenó la suspensión del procedimiento de la gestión judicial.

${ }^{10}$ Ley № 19.300 sobre bases generales del medio ambiente, de 1994 .

${ }^{11}$ Reclamo de Ilegalidad de Productos Del Mar Ventisqueros. S.A., interpuesto 22 el de agosto de 2018, Corte de Apelaciones de Santiago, Rol № 379-2018.
} 


\section{Dimensiones del problema jurídico debatido a la luz del derecho y la doctrina}

Es importante señalar que la Resolución del Consejo, se condice con el criterio de interpretación exhortado por la doctrina y jurisprudencia internacional del Sistema Interamericano de Derechos Humanos, que obliga a los Estados signatarios a garantizar el ejercicio pleno, progresivo y efectivo del Derecho de Acceso a la Información Pública (en adelante, DAIP). En este tenor, la Comisión Interamericana de los Derechos Humanos (en adelante; la Comisión) ${ }^{12}$ ha reconocido ampliamente que, en casos controvertidos por yuxtaposición de derechos como el planteado, la ley de acceso a la información debe prevalecer con preeminencia sobre otra legislación. Fundamentación jurídica que, repercute en el caso bajo análisis dado que guarda relación con el criterio de interpretación que privilegia el contenido del artículo 5o y 10 de la ley 20.285, por sobre el derecho del secreto industrial estatuido en el artículo 90 específicamente contemplado en la letra b), de la ley de propiedad industrial13.

Sin perjuicio de lo señalado por la doctrina y el derecho interamericano de los derechos humanos, conforme al criterio del Tribunal Constitucional los preceptos legales impugnados exceden y contraviene el artículo $8^{\circ}$ inciso 2 de la Constitución, por cuanto la ley introduce el concepto de información, expresión que no tiene cabida en la Constitución, como lo señala la Magistratura. En este sentido, de acuerdo a lo esgrimido en el considerando Vigésimo Quinto, el Consejo obligó a SERNAPESCA “(...) a entregar información de una forma distinta de la prevista en el ordenamiento legal, debiendo realizar operaciones distintas, tales como procesar, sistematizar, construir o elaborar un documento nuevo o distinto”, lo que según el justiciable, se aparta del precepto constitucional $8^{\circ}$ inciso segundo ${ }^{14}$.

En este tenor, es importante traer a consideración, que este análisis no recae sobre la legitimidad del tribunal respecto a la atribución de control constitucional per se, sino en la interpretación descontextualizada y regresiva del DAIP. Frente a este argumento, es importante recalcar que las normas en cuestión han sido reiterativamente declaradas inconstitucionales, por cuanto: “(...) extienden o amplían la información a que se puede tener acceso” basándose en una pretensión de extensión documental que, según lo describe la Sentencia bajo análisis: “amplía el objeto del acceso a la información. Hasta el punto de que toda ella sería pública,

\footnotetext{
${ }^{12}$ Declaración conjunta ONU, OEA y OSCE convinieron los Principios sobre Libertad de Expresión y Acceso a la Información, en una Declaración Conjunta de fecha 19 de diciembre de 2006.

${ }^{13}$ Ley de Propiedad Industrial D.F.L. N. 3, de 2006.

${ }^{14}$ Tribunal Constitucional, Rol 7425-2019-INA, de fecha 19 de diciembre 2019, considerando $18^{\circ}$ - 25ㅇ․
} 
independientemente de si tiene o no relación con el comportamiento o las funciones del órgano de la Administración"15.

En este punto es pertinente traer a la discusión, el verdadero sentido teleológico del legislador del 2008, cuando adoptando criterios de interpretación imperantes en del derecho convencional interamericano de los derechos humanos impulsado por la Comisión ${ }^{16}$ le atribuyó naturaleza jurídica de bien público, a la información elaborada con presupuesto del Estado, a menos que esta, recaiga sobre alguna de las excepciones constitucionales y legales taxativas, que dicho sea; no es el caso en cuestión. Conforme a ello, podría pensarse prime facie que en Chile la ley garantiza el ejercicio efectivo del DAIP, a través de la institución de la transparencia activa, lo que se reconoce por la doctrina comparada, bajo la institucionalidad de la transparencia administrativa explicada por Meijer, Hart y Worthy ${ }^{17}$ intrínsecamente dentro del marco conceptual de la transparencia en su doble dimensión: político-constitucional y administrativa.

Es decir, la transparencia de la función pública concebida, por una parte, como un derecho constitucional subjetivo atribuido a toda persona que le faculta a solicitar información a cualquier órgano del Estado y, por otra parte, como una obligación de estos de entregarla efectivamente, está en riesgo como consecuencia del retroceso jurisprudencial del tribunal, que obstaculiza la efectiva participación activa de la sociedad civil como mecanismo de control social horizontal. Este doble ámbito de regulación, se garantiza a través de la ley 20.285 conforme a los dos principios rectores amparados por la Comisión ${ }^{18}$, es decir, de máxima divulgación y de buena $f e$, pese que la justicia constitucional insiste en declarar inaplicables los preceptos normativos en donde se regula sustantivamente derechos fundamentales neoconstitucionales ${ }^{19}$.

\section{Argumentos de la Sentencia por los que se declara la inaplicabilidad del artículo $5^{\circ}$ inciso $2^{\circ}$ y el artículo 10 inciso $2^{\circ}$ de la ley 20.285}

\footnotetext{
15 Tribunal Constitucional, Rol 7425-2019-INA, de fecha 19 de diciembre 2019, Considerando 21ㅇ.

${ }^{16}$ CIDH (2010). Relatoría Especial para la Libertad de Expresión (RELE), El derecho de acceso a la información en el marco jurídico interamericano, párr. 10.

${ }^{17}$ Meijer, Hart y Worthy (2015), pp. 3-5. Worthy (2010), p. 564.

18 Principios del Comité Jurídico Interamericano, CJI/RES. 147 (LXXIII-0/08); Mendel (2009): “La definición completa de la transparencia, es entendida como un "principio rector dirigido a erradicar la cultura arraigada de secreto gubernamental, (...) al alero del derecho a la información depende de cambiar esta cultura, virtualmente imposible de obligar a los servidores públicos a ser francos/as, incluso con la legislación más progresista", p.42. Del mismo modo, por la CIDH (2010), p. 13.

${ }^{19}$ Buriticá-Arango (2019), p. 870.
} 
El tribunal cuando declaró que el requerimiento de inaplicabilidad ha de ser íntegramente acogido, lo hizo sobre las siguientes razones de fondo. En primer lugar, alega que ha sido un criterio sostenido en varios pronunciamientos por la Magistratura, es decir, atribuye efectos de cosa juzgada formal al tema debatido, antes de considerar otros argumentos de fondo y la interpretación progresiva de los derechos fundamentales ${ }^{20}$. En este aspecto, el tribunal parte de un principio de no variabilidad de su interpretación por tratarse de una tendencia jurisprudencial, atribuyendo extensivamente una competencia que no está regulada expresamente por la constitución. Sin embargo, resulta paradójico que trece años después que Claude Reyes y otros contra Chile, obtuvieron por sentencia de la Corte Interamericana de los Derechos Humanos la restitución del DAIP21, el Tribunal Constitucional mantenga una línea jurisprudencial inmodificable a la fecha, que declara inaplicables - a las causas particulares que así lo requieran- preceptos legales garantes de derechos fundamentales, basándose en la naturaleza privada/pública de la información solicitada.

En segundo lugar el tribunal también alega, que el contenido material de la ley 20.285 y por consiguiente la ley 19.300, en lo relativo a la regulación del derecho de acceso a la información pública medioambiental, incorporan en el texto legal una expresión que excede del dispositivo constitucional estatuido en el artículo 8oㅡ. reducida a: "[una] tendencia plasmada en dicha ley" 22. En este aspecto, es importante mencionar que la precitada "tendencia", tal como la caracteriza el tribunal, es una garantía del orden constitucional republicano, sobre las que subyace la institucionalidad de la democracia.

En este aspecto coincidimos con Nogueira Alcalá23 y, abogamos por la aplicación "del derecho convencional internacional de los derechos humanos en la jurisprudencia del tribunal constitucional" como una constante en el ámbito regional americano, donde la interrelación entre derecho constitucional y derecho internacional de los derechos humanos, adquiere una dimensión especial y estrecha, constituyendo una verdadera fusión y un único sistema de derechos, los cuales se sustentan de la fuente interna constitucional y de las fuentes del derecho internacional. En otras palabras, los derechos humanos hoy día son objeto de reconocimiento,

\footnotetext{
20 Torres (2015), p. 95.

${ }^{21}$ Sentencia Claude Reyes y otros contra Chile, Sentencia de la Corte Interamericana de los Derechos Humanos, de fecha 19 de septiembre 2006, Serie C, número 151, párrafos 86 y 87 . En este mismo sentido, Informe de la Rel atoría especial de libertad de expresión (RELE), de la Comisión Interamericana de los Derechos Humanos, de 2010, p. IX.

22 Tribunal Constitucional Sentencia Rol № 7425-19-INA, de fecha 19 de septiembre de 2019, considerando 19 ‥

${ }^{23}$ Nogueira (2012), Reconoce que en el bloque regional existe un "ius commune regional que forma parte del orden público latinoamericano que los Estados Partes deben asegurar y garantizar a las personas sometidas a su jurisdicción y que muchos pa íses de la región han constitucionalizado" p. 152.
} 
garantía y protección, tanto por parte del derecho constitucional como, del derecho internacional de los derechos humanos. Esta dualidad "ha permitido la elaboración doctrinaria del tema de los derechos humanos, desde ambas perspectivas. Sin embargo, aun así, se advierte que el tema de los derechos humanos no puede ser abordado exclusivamente por el derecho internacional ni por el derecho constitucional, sino por un método multidisciplinario"24.

Profundizando el análisis respecto al criterio del tribunal, consideramos que representa un flagrante incumplimiento de estándares internacionales interamericanos de los derechos humanos ${ }^{25}$, especialmente en lo que respecta al derecho a buscar y recibir información como parte del derecho a la libertad de pensamiento y expresión reconocido en el artículo 19 de la Declaración Universal de los Derechos Humanos, el artículo 19 del Pacto Internacional de Derechos Civiles y Políticos, el artículo 13 de la Convención Americana sobre Derechos Humanos, y el artículo 4 de la Declaración Americana de los Derechos y Deberes del Hombre.

En tercer lugar, en otro de los considerandos el tribunal señala como punto principal, que de no limitarse el ámbito de aplicación la ley —vale decir, objeto o bien jurídico tutelado relacionado con el acceso a la información pública - implica que toda la información que obra en poder de los órganos del Estado, reúne las características de bien público, dado que: "resulta difícil imaginarse una información que no esté comprendida en alguna de las dos categorías que el precepto establece, porque la Administración o produce información o la posee a algún título"26. Respecto a este argumento, señala el tribunal más adelante lo siguiente: "si el artículo 8o constitucional hubiera querido hacer pública toda la información que produzca o esté en poder de la administración, no hubiera utilizado las expresiones acto, resolución, fundamentos, y procedimientos", bajo la premisa que la enumeración de estas expresiones fue, precisamente limitar aquello que específicamente se quiere hacer público ${ }^{27}$. Con relación a este aspecto, conviene advertir que esta posición del tribunal se aleja de la doctrina y del derecho internacional de los derechos humanos vigente catalogadas por el Sistema Interamericano, como evidencia in factum de una interpretación judicial regresiva de los derechos fundamentales ${ }^{28}$,

\footnotetext{
${ }^{24}$ Ayala (2002), pp. 37 - 38.

${ }^{25}$ Ley Modelo Interamericana sobre Acceso a la Información de 2016; Convención sobre el acceso a la información o Convenio de Aahrus, de fecha 17 de febrero de 2005; Informe sobre indicadores para vigilar el cumplimiento de los instrumentos internacionales de derechos humanos de la Organización de las Naciones Unidas, HRI/MC/2006/7, de fecha 15 de mayo de 2008.

26 Tribunal Constitucional Sentencia Rol № 7425-19-INA, de fecha 19 de septiembre de 2019, considerando $21^{\circ}$.

27 Tribunal Constitucional Sentencia Rol № 7425-19-INA, de fecha 19 de septiembre de 2019, considerando 24ㅇ․

${ }^{28}$ Organización de las Naciones Unidas (HRI/MC/2006/7), de fecha 15 de mayo de 2008.
} 
constitutiva de una barrera para el efectivo control social, sobre prácticas de secreto y reserva de la Administración.

En este sentido, advertimos que somos de la opinión que la resolución del Consejo es coherente con el marco jurídico del derecho interamericano, basándonos en la doctrina e interpretación esgrimida por la Comisión quien, en forma sistemática y reiterada en sus Informes de los años 2010, 2012 y 2015, ha esgrimido que es una obligación de los Estados adoptar medidas para promover, implementar y asegurar el derecho de acceso a la información pública en forma progresiva. Del mismo modo que, con los compromisos de la Organización Económica para la Cooperación y el Desarrollo² ${ }^{29}$, también conocida por las siglas OCDE, quien recomienda prácticas de transparencia y rendición de cuentas, como mecanismos esenciales para el desarrollo, Organización internacional de la cual Chile forma parte desde el año 2010. De manera similar, la Convención de Naciones Unidas Contra la Corrupción (UNCAC) ${ }^{30}$ que, exige adoptar medidas apropiadas para promover la transparencia, a través del respeto, promoción y protección de la libertad de buscar, recibir, publicar y difundir información relativa a la corrupción.

Al final, este concierto de instrumentos internacionales resultan contrariados por la posición del Tribunal Constitucional, que insiste en: declarar la inaplicabilidad del contenido $5^{\circ}$ y 10 de la ley por razones de inconstitucionalidad, dado que, bajo sus consideraciones podrían exponer información ambiental que obra en poder del Estado, protegida por las causales de reserva establecidas en el artículo 8o constitucional, con el argumento que dichos preceptos jurídicos, amplían el alcance del derecho de acceso, según el cual, es pública toda información que obra en poder de SERNAPESCA, inclusive la entregada por particulares en medio de un procedimiento de fiscalización legítimamente establecido.

En cuarto lugar, el fallo contraviene uno de los principios sobre los que se funda la nueva filosofía de gobierno abierto ${ }^{31}$, mediante la cual Chile como Estado adherente de la Alianza para el Gobierno Abierto desde el año $2011^{32}$, se comprometió a la promoción, respeto y realización

\footnotetext{
29 OCDE (2008), Recommendation of the Council for Enhanced Access and More Effective Use of Public Sector Information (OECD/LEGAL/0362) [Disponible en: https://bit.ly/3vGoiC4], p. 5.

${ }^{30}$ Convención de Naciones Unidas Contra la Corrupción (UNCAC) de 2003. En el mismo sentido, Convención de la OCDE vigente desde el 15 de febrero de 1999.

${ }^{31}$ Sandoval (2015), p. 205. En este sentido, citando a Richardson (1973) afirma que la libertad de información es un componente básico del proceso democrático; de acuerdo con esta idea llamada "derecho de saber" (right to know), es lo opuesto al secreto gubernamental.

32 Declaración de Gobierno Abierto, de la Alianza Global de países comprometidos con los principios consagrados en la Declaración Universal de los Derechos Humanos, la Convención de las Naciones Unidas contra la Corrupción y otros instrumentos
} 
de la cultura de la transparencia, mediante el incremento de la disponibilidad de información sobre las actividades gubernamentales. Finalmente, es importante mencionar que además de los criterios de inaplicabilidad por los que declara la inconstitucionalidad de los preceptos impugnados, en el mismo cuerpo del fallo el tribunal alega en el considerando Vigésimo Quinto, lo que podría interpretarse como un criterio contradictorio de sus propias afirmaciones, cuando señala lo siguiente: “(...) la obligación de la Administración se limita a (...) proporcionar o entregar lo requerido [conforme al] artículo 16, Ley de Transparencia)"33. El texto citado, implícitamente reitera la obligación de proporcionar la información conforme al principio de apertura o transparencia establecido en el artículo 11, literal c) de la ley 20.285, que involucra que toda la información en poder de los órganos de la Administración del Estado se presume pública, lo que podría dar cabida al reconocimiento progresivo del principio de la transparencia en sus dos dimensiones, vitalizando la concreción de la transparencia y del derecho de acceso a la información pública, como fundamento de la institucionalidad democrática ${ }^{34}$.

\section{Comentarios Finales}

Vistos los argumentos de la Sentencia, la posición de este comentario se aparta de la interpretación del Tribunal Constitucional, donde declara la inaplicabilidad del artículo 5o y 10 de la ley 20.285, bajo el argumento que las disposiciones normativas impugnadas contravienen el precepto constitucional del artículo $8^{\circ}$ inciso $2^{\text {o }}$. En el mismo orden de ideas, lo explica la Ministra Marisol Peña Torres, en la Sentencia Rol 3111-16-INA, cuando en los argumentos de su voto de rechazo señala que las normas impugnadas no producen una aplicación contraria a la Constitución, pues ellas permiten el ejercicio legítimo de un derecho reconocido implícitamente en la Carta Fundamental que, el mismo Tribunal Constitucional ha reconocido en los siguientes términos: “(...) si bien el principio de transparencia, no ha sido reconocido expresamente por la constitución, en efecto, su propósito es garantizar el régimen democrático y el control del poder, obligando a las autoridades a responder de sus actos y dar cuenta de ellos (...)"35. En forma similar en la Sentencia Rol № 7425-19-INA, cuando los ministros disidentes fundamentan en el voto de rechazo, lo siguiente: “la interpretación que se haga del artículo 8o inciso 2o constitucional no puede restar eficacia al ejercicio del derecho de acceso a la información

\footnotetext{
internacionales relacionados con los derechos humanos y el buen gobierno, impulsado por el Presidential Memorandum on Transparency and Open Government - Interagency Collaboration, de 2009.

33 Tribunal Constitucional Sentencia Rol № 7425-19-INA, de fecha 19 de septiembre de 2019, considerando 25ㅇ․

34 Boletín 8805-07, de 24 de enero de 2013.

35 Tribunal Constitucional voto disidente de la Sentencia Rol № 3.111-16-INA, de fecha 23 de marzo de 2017, considerando 4으.
} 
pública, consagrado en el artículo 19ํㅜ Número $12^{\circ}$ de la constitución, indispensable para la garantía de una sociedad libre y democrática".

En síntesis, podemos señalar que la Sentencia se aparta del reconocimiento progresivo del DAIP, dado que el artículo $8^{\circ}$ no es el techo normativo de la publicidad de los actos de la administración pública como se afirma en el fallo, por lo que su interpretación debe ser adecuada progresivamente, en virtud, que contiene en esencia, el principio teleológico de la regulación de la publicidad de los actos de la administración 36 , habida cuenta que la Resolución del Amparo del Consejo, que dio lugar al Recurso de Reclamación por Ilegalidad, interpuesto por Productos del Mar Ventisqueros S.A. por ante la Corte de Apelaciones de Santiago, basado en la presunción, que la información requerida es pública porque obra en poder de un órgano del Estado. A nuestro entender, la posición del tribunal obstaculiza el ejercicio efectivo de un derecho subjetivo, ámbito material del accountability ciudadano ${ }^{37}$, es decir, control social de cuya materialización depende el valor de la democracia en sentido sustantivo, y forma parte de un movimiento universal caracterizado por una ola de reformas legislativas en temas de probidad y transparencia, dado sus efectos en múltiples dimensiones, entre los que destaca la mitigación del flagelo de la corrupción ${ }^{38}$.

Por otra parte, declarar la inconstitucionalidad de las normas controvertidas significa desconocer la función de control previo del tribunal, quien ya declaró preliminarmente en el año 2008 el reconocimiento constitucional del artículo 5o y 10 de la ley, en la Sentencia Rol № 105108-CPR, en pleno ejercicio de la atribución legítimamente conferida en el artículo 93, numeral $1^{\text {o }}$ de la Constitución ${ }^{39}$. Adicionalmente, de continuar el tribunal con este criterio de interpretación insuficiente, desconoce la esencia de la fundamentación del bien jurídico controvertido, el cual teleológicamente guarda relación con el deber de salvaguardar el sistema de pesos y contrapesos del ejercicio del poder público, que obliga a las autoridades a responder a la sociedad de sus actos y dar cuenta de ello, de igual forma, que promover la responsabilidad de los funcionarios sobre la gestión pública, y en consecuencia, fomentar la participación de las personas en asuntos de interés de toda la sociedad ${ }^{40}$.

\footnotetext{
${ }^{36}$ Tribunal Constitucional voto disidente de la Sentencia Rol № 7425-19-INA, de fecha 19 de septiembre de 2019, considerando 9o en las argumentaciones de la disidencia.

${ }^{37}$ Hood (2010), p. 995.

${ }^{38}$ Ackerman y Sandoval (2008), p.13.

${ }^{39}$ Sentencia del Tribunal Constitucional, Rol № 1051-08-CPR, de 11 de julio de 2008.

${ }^{40}$ Schedler (2008), p.9.
} 
En conclusión, es importante reiterar que en la publicidad de los actos y resoluciones de los órganos de la administración pública —entiéndase; información pública que obra en poder de los órganos del Estado- , reside uno de los principios democráticos del régimen republicano, y lo contrario, es decir, no reconocerlo, significa una regresión de la justiciabilidad constitucional que retrotraerá a Chile a la situación original conminada por Sentencia de la Corte Interamericana en el año 2006, antes del reconocimiento del DAIP por el ordenamiento jurídico vigente, mediante la promulgación de la ley 20.285 en el año 2008. Como corolario, es importante precisar que la interpretación constitucional en este caso, desconoce cambios significativos suscitados en torno al DAIP en el derecho internacional de los derechos humanos, de igual forma que el desconocimiento de obligaciones pactadas legítimamente por el país, socavando la tradición demócrata republicana, y desconociendo la naturaleza dual del principio de transparencia, que no solo está dirigida a proporcionar información que obra en poder de los órganos del Estado provistas por privados, sino además, proteger otros bienes jurídicos públicos específicamente relacionados con el orden democrático constitucional ${ }^{41 .}$

Como se ha dicho de continuar el Tribunal Constitucional con esta posición, establece barreras para el ejercicio efectivo de derechos fundamentales, que tal como lo explica Dworkin ${ }^{42}$, representan derechos sustanciales, considerados como presupuestos fundacionales de la democracia, por tanto, su lectura material lleva la moralidad política al corazón del derecho constitucional, para ello, propone que antes de negar un derecho fundamental se debe, considerar además del sentido gramatical, la intención o propósito del texto legal, dado que la jurisdicción no gira solamente en torno de enunciados normativos incompletos ${ }^{43}$. Recapitulando, el criterio jurisprudencial comentado se aleja de la justiciabilidad progresiva del DAIP, por dos razones principalmente. Por una parte, tal y como lo explica Bayón ${ }^{44}$ por desconocer que: "la sociedad no es la misma a lo largo del tiempo". Y, por otra parte, por invocar un enunciado semántico literal insuficiente, para realizar una interpretación de la Constitución ${ }^{45}$.

A modo de reflexión final, basta con hacer memoria de las razones materiales que dieron lugar a la reforma del artículo 8º constitucional en el año 2005, la cual se centró precisamente

\footnotetext{
${ }^{41}$ Fung y Weil (2010), p. 106.

${ }^{42}$ Dworkin (1989), Cita completa: "En una democracia todo ciudadano tiene derecho a que promulguen leyes que garanticen su derecho a la libertad de expresión", p. 171.

${ }^{43}$ Dworkin (1996), pp. 17-23. Y en el mismo sentido, Alexy (1993), pp. 28-30.

${ }^{44}$ Bayón (2002), p. 78.

${ }^{45}$ Brink (1988), p. 128. El autor afirma, que el contenido semántico de las disposiciones normativas no es en ciertos casos, suficiente para realizar una interpretación adecuada de la constitución, dado que "abstract intentions, that is, the kinds of values, policies, and principles which the framers of the law were trying to realice".
} 
en incorporar estándares internacionales de la lucha contra la corrupción y el fortalecimiento de la probidad, principios basados en la publicidad de la información en poder los órganos del Estado. Lo contrario significaría desconocer los propósitos dominantes, del reconocimiento del marco legal e institucional del DAIP46, en un periodo controvertido del derecho constitucional latinoamericano caracterizado como un nuevo constitucionalismo basado en conquistas de derechos sociales, donde: "El cumplimiento de las leyes es más importante que su creación” 47.

\section{Bibliografía citada}

Ackerman, Jhon y Sandoval, Irma (2008): “Leyes de acceso a la información en el mundo”. En Cuaderno Número 07, Editorial IFAI, Instituto Nacional de Transparencia, Acceso a la Información y Protección de Datos Personales. México. [Disponible en: https://bit.ly/3qeihLQ] [fecha de la consulta 10 de septiembre 2018].

Alexy, Robert (1993): “Teoría de los derechos fundamentales”. Título original: Theorie Der Grundrechte. Suhrkamp-Verlag. Traducido por Ernesto Garzón Valdés. Revisión: Ruth Zimmerling. (Madrid, Centro de Estudios Constitucionales).

Ayala Corao, Carlos (2002): “La Jerarquía Constitucional de los Tratados Relativos a Derechos Humanos y sus Consecuencias". En: Derecho Internacional de los derechos humanos. Memoria del VII Congreso Iberoamericano de Derecho Constitucional. Coordinado por Ricardo Méndez Silva (México, Universidad Nacional Autónoma de México), pp.37-90.

Bayón, Juan Carlos (2002): “Democracia y Derechos: problemas de fundamentación del constitucionalismo", en Betegón, Jerónimo; Laporta, Francisco; De Páramo, Juan Ramón y Prieto Sanchís, Luis (edit.), Constitución y derechos fundamentales (Madrid, Centro de Estudios Políticos y Constitucionales).

Buriticá-Arango, Esteban (2019): “Interpretación constitucional, control judicial de la ley y desacuerdos", en Revista Chilena De Derecho (vol. 46, núm. 3), pp. 869-891.

Brink, David (1989): El realismo moral y los fundamentos de la ética (EEUU, Cambridge University Press).

${ }^{46}$ Ruiz-Rico (2019), p. 269.

${ }^{47}$ Gargarella (2015), p. 170; Thomas Jefferson, citado por Neuman (2006), p. 63. 
Dworkin, Ronald (1989): Los derechos en serio [Taking Rights Seriously]. (Barcelona, Editorial Ariel).

Dworkin, Ronald (1996): Ley de la libertad: la lectura moral de la Constitución estadounidense (Reino Unido, Oxford University Press).

Finol Romero, Lorayne (2019): Análisis De Impacto Regulatorio De La Transparencia De La Función Pública A Diez Años De La Ley 20.285, ponencia presentada en la XLIX Jornadas Chilenas de Derecho Público organizada por la Facultad de Derecho de la Universidad Pontificia Católica de Chile. Celebrada los días jueves 17 y viernes 18 de octubre del 2019, en Santiago de Chile.

Fung, Archon y Weil, David (2010): “Open government and open society. Open government: Collaboration, transparency, and participation in practice", en Lathrop, Daniel y Ruma, Luma eds. Open Government: Transparency, Collaboration and Participation in practice (USA: O’Really Media Inc), pp. 106-108.

Gargarella, Roberto (2015): “El nuevo constitucionalismo Latinoamericano", en Revista Uruguaya de Ciencia Política (Vol. 27, №1), pp. 169-174.

Hood, Cristopher (2010): “Accountability and transparency: Siamese twins, matching parts, awkward couple”, en West European Politics (Vol. 33), pp. 989-1009.

Neuman, Laura (2006): El Camino Hacia el Derecho de Acceso a la Información (Editado por Centro Carter, Atlanta, Estado Unidos]. https://bit.ly/2RzzEK8 [fecha de la consulta 9 de julio 2019].

Mendel, Toby (2009): El derecho a la información pública en América Latina: Comparación Jurídica (Francia, UNESCO).

Meijer, Albert; Hart, Paul y Worthy, Benjamin (2015): “Assessing Government Transparency: An Interpretive Framework", en Administration \& Society (Vol. 50, № 4), pp. 501-526.

Nogueira-Alcalá, Humberto (2012): “El uso del derecho convencional internacional de los derechos humanos en la jurisprudencia del Tribunal Constitucional chileno en el período 2006-2010", en Revista Chilena de Derecho (Vol. 39, № 1), pp. 149-197. 
Ruiz-Rico Ruiz, Catalina (2019): “Análisis comparativo de la legislación iberoamericana en materia de transparencia y derecho de acceso a la información", en Boletín mexicano de derecho comparado (Vol. 52, № 154), pp. 255-283.

Sandoval, Rodrigo (2015): “Gobierno abierto y transparencia: construyendo un marco conceptual”, en Convergencia Revista de Ciencias Sociales (Vol. 22, № 68), pp. 203-227.

Schedler; Andreas (2008): “Qué es la rendición de cuentas. IFAI. México. Schedler, A. (1999). Conceptualizing Accountability", en Schedler, L.J. Diamond y M. Plattner Eds. The Selfrestraining State: Power and Accountability in New Democracies (Boulder: Lynne Rienner), pp. 14-17.

Torres Zúñiga, Natalia (2015): “Justiciabilidad de las medidas regresivas de los derechos sociales. Algunas reflexiones acerca de su protección en América Latina”, en Revista Derecho PUCP ( $\left.\mathrm{N}^{\circ} 75\right)$, pp. 95-117.

Worthy, Benjamin (2010): “More Open but Not More Trusted? The Effect of the Freedom of Information Act 2000 on the United Kingdom Central Government, en International Journal of Policy, Administration, and Institutions (Vol. 23, No. 4), pp. 561-582.

\section{Normas jurídicas citadas}

Alianza para el Gobierno Abierto. Declaración de Gobierno Abierto. Disponible en: https://bit.ly/35bo1wh [fecha de consulta 7 de agosto 2017].

Boletín 8805-07, de fecha 24 de enero de 2013. Proyecto de reforma constitucional que otorga reconocimiento constitucional al principio de transparencia y el derecho de acceso a la información, DJ/UNR/07/03/2018.

Carta Democrática Interamericana, 28o Período Extraordinario, de 11 de septiembre de 2001.

Carta de los Derechos Fundamentales de la Unión Europea. Diario Oficial (2000/C 364/01 y C364/19).

Convención Americana sobre Derechos Humanos, Pacto de San José de Costa Rica, de 22 de noviembre de 1969. 
Convención de la OCDE para combatir el soborno de funcionarios públicos extranjeros en transacciones comerciales internacionales, firmada el 17 de diciembre de 1997, vigente desde el 15 de febrero de 1999.

Convención de Naciones Unidas Contra la Corrupción (UNCAC) de 2003, Resolución 58/4 de la Asamblea General, de 31 de octubre de 2003.

Declaración Universal de los Derechos Humanos. Asamblea General de las Naciones Unidas (ONU) en París, en Resolución 217 A (III), el 10 de diciembre de 1948.

Declaración conjunta de la ONU, OEA y OSCE. Principios sobre Libertad de Expresión y Acceso a la Información, de fecha 19 de diciembre de 2006, Resolución de la Asamblea General de la Organización AG-RES. 1932 (XXXIII-0-03).

Informe de la Relatoría especial de libertad de expresión (RELE), aprobada por la Comisión Interamericana de los Derechos Humanos, OEA/RELE/INF. 1/09, el 30 de diciembre de 2009.

Informe sobre indicadores para vigilar el cumplimiento de los instrumentos internacionales de derechos humanos de la Organización de las Naciones Unidas, HRI/MC/2006/7, de fecha 15 de mayo de 2008.

Ley Modelo Interamericana sobre Acceso a la Información. Aprobado por la Asamblea General de la OEA el 14 de junio de 2016, Resolución AG/RES. 2885 (XLVI-0/16).

Ley № 19.300, ley sobre bases generales del medio ambiente, Diario Oficial 1 de marzo de 1994, reformada por Ley № 20.473 donde se otorgan transitoriamente facultades fiscalizadoras y sancionadoras, el 13 de noviembre de 2010.

Ley 20.050, Reforma Constitucional Que Introduce Diversas Modificaciones A La Constitución Política De La República, Diario Oficial, 26 de agosto de 2005.

Ley № 20.285. Ley sobre Acceso a la Información Pública. Congreso Nacional de Chile, Diario Oficial, 11 de agosto de 2008.

Ley $\mathrm{N}^{\circ}$ 20.417, de 12 de enero de 2010. Crea El Ministerio, El Servicio De Evaluación Ambiental Y La Superintendencia Del Medio Ambiente, Diario Oficial, 12 de enero de 2010. 
Pacto Internacional de los Derechos Civiles y Políticos. Adoptado y abierto a la firma, ratificación y adhesión por la Asamblea General en su resolución 2200 A (XXI), de 16 de diciembre de 1966.

Principios sobre el derecho de acceso a la información, Comité Jurídico Interamericano, CJI/RES. 147 (LXXIII-0/08) de 7 de agosto de 2008.

\section{Jurisprudencia citada}

Consejo para la Transparencia: Oceanía Inc. contra el Servicio Nacional de Pesca y Acuicultura (SERNAPESCA) (Resolución de Amparo CPLT), Rol C1003-18 de 14 de marzo de 2018.

Corte de Apelaciones de Santiago: Productos del Mar Ventisqueros S.A. con Consejo para la Transparencia (Recurso Contencioso Administrativo), Rol № 379 - 2018, de 22 de agosto de 2018.

Corte Interamericana de los Derechos Humanos: Claude Reyes y otros contra Chile, en Serie C, número 151, de 19 de septiembre 2006.

Tribunal Constitucional de Chile: Asociación de la Industria del Salmón de Chile A.G. y otros (Requerimiento de Inaplicabilidad), Rol № 3111-16-INA. Voto disidente Ministra Doña Marisol Peña Torres, de 23 de marzo de 2017.

Tribunal Constitucional de Chile: (Control de constitucionalidad del proyecto de ley aprobado por el Congreso Nacional, sobre acceso a la información pública), Rol № 1051, de 10 de julio de 2008.

Tribunal Constitucional de Chile: Productos del Mar Ventisqueros S.A. con Consejo para la Transparencia, (Requerimiento de Inaplicabilidad), Rol 7425-19-INA, de 19 de diciembre de 2019.

Tribunal Constitucional de Chile: Productos del Mar Ventisqueros S.A. con Consejo para la Transparencia (Voto disidente de los Ministros Gonzalo García Pino, Domingo Hernández Emparanza, Nelson Pozo Silva, María Pía Silva Gallinato), Rol 7425-19-INA, de 19 de diciembre de 2019. 